\title{
113. SOBRE LA PRESENCIA DE STERNBERGIA LUTEA (L.) KER-GAWLER (AMARYLLIDACEAE) EN EXTREMADURA
}

\author{
Antonio CHAVES, Josefa LÓPEZ y Juan Antonio DEVESA
}

On the presence of Sternbergia lutea (L.) Ker-Gawler (Amaryllidaceae) in Extremadura.

Palabras clave. Sternbergia, Amaryllidaceae, corología, Extremadura, España.

Key words. Sternbergia, Amaryllidaceae, chorology, Extremadura, Spain.

Sternbergia lutea (L.) Ker-Gawler

Amaryllis lutea $\mathrm{L}$.

BADAJOZ: Zafra, finca El palomar, sobre sustrato calcáreo, $\pm 520 \mathrm{msm}, 38^{\circ} 25^{\prime} 61^{\prime \prime} \mathrm{N}, 6^{\circ}$ 25' 79" W, 4-10-2001, A. Chaves \& J. A. Devesa (UNEX 30406)

El cólquico o azucena amarilla es un elemento mediterráneo que se extiende hasta Asia Central, descrito en parte con material español ("Habitat in Hispania, Italia, Thracia") pero cuya representación en la Península Ibérica es muy escasa. Para la flora española se conoce de las Islas Baleares (Mallorca) y de algunas provincias del centro y sur de la Península [Ca Cc Co Gr J M Mu Sa Se Sg To Va], donde no es muy abundante [Blanca \& Valle in Bol. Soc. Brot. sér. 2, 53(2): 1030-1034, 1981; Willk. in Willk. \& Lange, Prodr. Fl. Hispan. 1: 147, $1861]$.

Aunque no recogida su presencia en la flora de Extremadura [Tormo, Amaryllidaceae, in Devesa, Fl. Extremadura: 636-639, 1995], se conoce su existencia en la provincia de Cáceres [Almaraz de Tajo, 5-10-1976, E. Rico, MA 203634], testimonio al que hay que sumar también la población pacense indicada, que amplía el conocimiento corológico del taxon. Aquí, los individuos aparecen en enclaves abiertos y pedregosos, aislados o formando pequeños rodales, muy próximos a antiguos abancalamientos y viviendas, hoy día abandonadas, que ponen de manifiesto el carácter subespontáneo de esta población que aparentemente está en proceso de expansión por vía vegetativa.

Aceptado para su publicación en marzo de 2002

Dirección de los autores. Departamento de Biología y Producción de los Vegetales (Botánica), Facultad de Ciencias, Universidad de Extremadura, 06071 Badajoz. 